\title{
Relato de experiência de intercâmbio voluntário no Instituto Nacional de Saúde da Criança, Lima - Peru
}

\author{
Report of volunteer exchange experience at the Institute \\ National Children's Health, Lima - Peru
}

\author{
Informe de experiencia de intercambio de voluntarios en el Instituto \\ Salud Nacional del Niño, Lima - Perú
}

\section{Evelyn Ortiz Campos', Vanessa Ramos Kirsten"}

\author{
I Acadêmica do Curso de Nutrição da Universidade Federal de Santa Maria - UFSM
}

II Professora do Departamento de Alimentos e Nutrição da UFSM. Doutora em Saúde da Criança e do Adolescente pela UFRGS

\begin{abstract}
RESUMO
O presente relato tem o objetivo de descrever as vivências de intercâmbio voluntário desenvolvido por uma acadêmica de nutrição no Instituto Nacional de Saúde da Criança (Instituto Nacional de Salud Del Niño), na cidade de Lima, Peru, no período de fevereiro a março de 2020. As atividades realizadas durante a participação no Programa Lá Compañía, tiveram o intuito de acompanhar crianças e adolescentes hospitalizados, fornecendo apoio educacional e recreativo, a fim de contribuir no bem estar e no suporte emocional aos pacientes. Neste local houve o conhecimento do funcionamento da saúde pública do país, a troca de experiência entre estudantes intercambistas de vários países, além de atividades culturais. A realização do intercâmbio trouxe a estudante diversas vivências que forneceram ganhos profissionais e crescimento pessoal com o desenvolvimento ligado ao altruísmo.
\end{abstract}

Palavras-chave: Intercâmbio de Conhecimento. Trabalho Voluntário. Criança Hospitalizada. Saúde Pública.

\section{ABSTRACT}

Thus report aims to describe the experiences of voluntary exchange developed by a nutrition student at the National Institute of Child Health (Instituto Nacional de Salud Del Niño), in the city of Lima, Peru, from February to March 2020. The activities carried out while participating in the Lá Compañía Program, were intended to accompany hospitalized children and adolescents, providing educational and recreational support in order to contribute to the weel-being and provide emotional support to patients. In this place there was knowledge of the functioning of public health in the country, the exchange of experience between exchange students from various countries, in addition to cultural activities. The exchange brought the student several experiences that provided professional gains and personal growth with the development linked to altruism. 
Keywords: Exchange of Knowledge. Volunteer Work. Hospitalized Child. Public health.

\section{RESUMÉN}

Este informe tiene como objetivo describir las experiencias de intercambio voluntario desarrolladas por una estudiente de nutrición en el Instituto Nacional de Salud Del Niño, en la ciudad de Lima, Perú, de febrero a marzo de 2020. Las actividades realizadas durante el participación en el Programa Lá Compañía, tenían como objetivo acompañar a los niños y adolescentes hospitalizados, brindándoles apoyo educativo y recreativo con el fin de contribuir al bienestar y apoyo emocional de los pacientes. En este lugar se conoció el funcionamiento de la salud pública en el país, el intercambio de experiencias entre estudiantes de intercambio de vários países, además de actividades culturales. El intercambio trajo al alumno varias experiencias que Le proporcionaron ganâncias profesionales u crecimiento personal con el desarrollo vinculado al altruismo.

Palabras clave: Intercambio de conocimientos. Trabajo voluntario. Niño hospitalizado. Salud pública.

\section{INTRODUÇÃO}

A palavra intercâmbio expressa reciprocidade de relações tanto culturais como educacionais entre nações, sendo assim, tal vivência contribui para o desenvolvimento no âmbito profissional e pessoal do intercambista. No que tange o meio acadêmico a prática de intercâmbio de conhecimento vai além de aperfeiçoamento linguístico e de todo aprendizado envolvido, sendo, um meio de estimular o amadurecimento, autoconfiança e criar uma visão ampliada de futuro (SOUZA, 2008; CARVALHO, 2016).

Ao falar em trocas, ganhos pessoais e profissionais a palavra voluntário pode estar relacionada ao assunto, tendo como conceito o ato de doar tempo e conhecimento para prestação de serviços não remunerados em prol da comunidade, devido impulso solidário e interesse pessoal. Pois, não somente a solidariedade move o voluntariado, mas também o altruísmo ligado ao assistencialismo, juntamente ao benefício pessoal adquirido (AZEVEDO, 2007).

Ações extensionistas são oportunidades de ensino-aprendizagem em ambientes fora da universidade que contribuem para a formação acadêmica de estudantes, principalmente da área da saúde, pois ao se deparar com a realidade da 
população, a experiência produz sensibilidade social, cultural e consciência política. A extensão, através dos trabalhos voluntários e atividades complementares o acadêmico consegue obter interações fidedignas com a comunidade, aspecto essencial para uma intervenção bem sucedida, além de compreender os problemas sociais, agrega valor ao currículo de graduação (PEREIRA, 2011; WARMLING, 2012).

De acordo com Carvalho (2016) estudantes motivados buscam cada vez mais participar nestes processos, através de organizações. Sendo uma delas a Association Internationale des Etudiants et Commerciales (AIESEC), reconhecida pela Organização das Nações Unidas para Educação, a Ciência e a Cultura (UNESCO) como o maior movimento de liderança jovem do mundo, que visa o desenvolvimento de potencialidades humanas através de intercâmbios profissionais e voluntários. Ofertando a modalidade Voluntário Global que ocorre em organizações não governamentais (ONGs), escolas ou em fundações de diversos países, com o intuito de engajar e empoderar pessoas (AIESEC, 2020).

O acadêmico de modo geral está exposto ao conhecimento, logo, a aspiração para realização deste intercâmbio voluntário baseia-se no intuito de adquirir conhecimentos que vão além dos muros das universidades e das fronteiras do nosso país, juntamente com o desejo de conhecer o berço de uma das civilizações mais antigas da América do Sul, aprender um novo idioma, exercer a função de aprendiz em um cenário desafiador e impactar vidas.

Diante do exposto, o objetivo deste artigo é relatar os momentos vivenciados durante o intercâmbio e o trabalho voluntário no Instituto Nacional de Saúde da Criança em Lima, Peru. Salientando as atividades realizadas com crianças hospitalizadas, a identidade social e cultural do país bem como os conhecimentos adquiridos durante o intercâmbio.

\section{DESENVOLTIMENTO}

\subsection{Planejamento do intercâmbio}


Por intermédio da AIESEC de Santa Maria no estado do Rio Grande do Sul, realizou-se a organização para o intercâmbio voluntário no Instituto Nacional de Saúde da Criança, na cidade de Lima, Peru, tendo início no dia 03 de fevereiro ao dia 13 de março de 2020, totalizando 85 horas. O trabalho executado ocorreu no Programa de Pedagogia Hospitalar La Compañía que tem como objetivo fornecer apoio educacional e recreativo as crianças hospitalizadas.

Dois meses antes da data do embarque iniciou-se a preparação para o intercâmbio com apoio dos membros da AIESEC, nesse período ocorreram duas reuniões abordando os seguintes temas: Apresentação sobre o país e o programa, itens necessaries para viagem, organização dos documentos, planejamento financeiro e roda de conversa com estudantes que já realizaram intercâmbio voluntário.

\subsection{Chegada na sede AIESEC em Lima no Peru}

Após chegada ao Peru na cidade de Lima, foi marcada uma reunião na Pontifícia Universidad Católica Del Peru (PUCP) apoiadora da AIESEC, para boas vindas, apresentação dos intercambistas e breve estudo sobre os costumes peruanos, abordando a economia, cultura, culinária e pontos turísticos, além de formas de interagir com o público atendido em cada projeto.

Ao todo, o grupo de voluntários era formado por 5 brasileiros, 2 mexicanos e 1 colombiano, os quais foram encaminhados para distintos projetos de acordo com sua formação acadêmica, sendo estes projetos relacionados a educação, saúde e meio ambiente. Os estudantes das áreas da saúde e educação foram direcionados para o Programa Lá Compañía e, o restante para um programa de sustentabilidade.

\subsection{Programa La Compañia}

O Programa La Compañía faz parte da associação sem fins lucrativos Abrazarte: La Magia Del Encuentro, juntamente com o programa Padrinos Azules, ambos com o intuito de prestar assistência a pessoas hospitalizadas. O Programa teve início em novembro de 2013 no Instituto Nacional de Salud Del Niño, onde começou-se a 
realizar as atividades com o apoio de voluntários e intercambistas, com o propósito de acompanhar as crianças e adolescentes hospitalizados, impulsionar o conceito de pedagogia hospitalar, promover o direito à educação para todos, contemplados na Constituição Peruana e dar suporte emocional aos pacientes e se necessário a família.

La Compañía conta com a coordenação geral de Marta Chaves Bellido, psicóloga, pedagoga e docente na Pontificia Universidad Católica Del Peru (PUCP), responsável por ministrar a disciplina Familia, Educación y Comunidad. Além da coordenadora geral, possui também as coordenadoras responsáveis por cada ala de atendimento, as quais conduzem os voluntários.

O projeto atende os pacientes da neuropediatria, neurocirurgia, cirurgia geral, de tórax, cabeça e pescoço, cardiologia e os pacientes queimados os quais são chamados de valentes. Ocupa uma sala na área de psicopedagogia, com espaço para reuniões, confraternizações, preparo das atividades e acondicionamento dos materiais utilizados. Além dos voluntários fixos, possui voluntários transitórios que são os intercambistas que vem através de várias organizações. No período do intercâmbio a equipe do projeto era formada por 4 brasileiros, 1 americano, 2 alemãs, 1 mexicano e 1 colombiano, o restante eram voluntários peruanos.

\subsection{Instituto Nacional de Saúde da Criança}

O Instituto Nacional de Salud Del Niño (INSN) é uma das primeiras instituições públicas do país, considerado um centro de referência nacional de pediatria que presta serviços a $70 \%$ da população infantil de todo o Peru. Oferece uma atenção especializada e focada no paciente, na família e na comunidade, apostando no uso de novas tecnologias, fortalecimento dos recursos humanos e impulsionando a investigação cientifica e a docência (INSN, 2020).

A instituição foi inaugurada em 01 de novembro de 1929, com mais de 8 décadas de história, possui cerca de 3 mil trabalhadores. Recebe diariamente 1400 crianças por consulta externa e 250 por emergência, conta com aproximadamente 500 leitos para hospitalização e mais de 40 especialidades em que, as mais requisitadas são 
neuropediatria, traumatologia, endocrinologia, cardiologia, pneumologia, nefrologia, dermatologia e odontologia. Realiza procedimentos de alta e média complexidade como cirurgia geral, neurocirurgia, cirurgia plástica e reconstrutiva, cirurgia de tórax, cardiovascular, de cabeça e pescoço (INSN, 2020).

O sistema de saúde do Peru possui dois setores, o público e o privado para prestação de serviços de saúde. O setor público divide-se em regime contributivo subsidiado e regime contributivo direto. O governo oferece serviços de saúde à população não segurada por meio do Seguro Integral de Saúde (SIS), que subsidia a prestação de serviços para aqueles que vivem em condições de pobreza e extrema pobreza e a população já segurada ao SIS, através da rede de estabelecimentos do Ministérios da Saúde (MINSA) com hospitais e institutos especializados nas regiões e na capital do país (WILSON, 2009; APS, 2013).

Devido ao Instituto Nacional de Saúde da Criança, ser um hospital público gerido principalmente com recursos do SIS os usuários, de modo geral, encontram-se em situações de vulnerabilidade, e por ser referência em saúde da criança a nível nacional, há uma grande procura de seus serviços por toda a população peruana. Frente a isso, os profissionais da saúde devem estar devidamente preparados para atender tais cidadãos, levando em consideração a região de origem de cada paciente. Sendo que os peruanos da costa, da serra e da selva possuem diferenças culturais entre eles, desse modo os voluntários que acompanham tais pacientes também devem estar preparados para articular com cada um deles.

\subsection{Atividades como voluntária}

O voluntariado teve duração de seis semanas, tendo início dia 3 de fevereiro e término dia 13 de março de 2020, cumprindo ao final a carga horária de 85 horas como professora hospitalar. As atividades executadas nas alas hospitalares visitadas resumiam-se em brincadeiras e jogos educativos, pinturas, recortes, confecções de cartas, bolsas e caixas, exercícios de matemática e português, leitura de histórias e de modo geral companhia, inclusive apoio emocional aos pacientes e familiares, em relação ao sofrimento causado pelas enfermidades. 
As atividades eram escolhidas na sala do projeto, onde a coordenadora separava de acordo com a idade e estado de saúde dos pacientes, enquanto isso os voluntários se responsabilizavam pela criação de novas atividades educacionais. Quanto à execução das mesmas, era necessário treinar antes para melhor aplicá-las. O trabalho era supervisionado pela responsável de cada ala e todos os quartos possuíam um enfermeiro presente.

As brincadeiras, jogos e trabalhos manuais realizados com as crianças hospitalizadas têm o intuito de desenvolver a socialização, linguagem e criatividade. Através das confecções de materiais, os pacientes conseguem expressar seus sentimentos e ideias, aliviando a tensão que o ambiente proporciona. Devido a isso, todas as atividades realizadas pelas crianças, desde pintar, desenhar e confeccionar possui efeito terapêutico (POLETI, 2006).

Após a primeira semana de visitas nas alas hospitalares, criou-se maior vínculo com as crianças da neurocirurgia, devido ao sentimento recíproco de carinho, respeito e amizade. Em conjunto com a coordenadora pedagógica responsável a autora do artigo optou por acompanhar diariamente essas crianças, dividindo o tempo entre elas. Em cada quarto encontravam-se internadas de 5 a 6 crianças, com idades variadas. As atividades eram executadas somente com crianças acima de 2 anos.

Alguns dias da semana ocorriam visitas no quinto andar na UCI, Unidade de Cuidados Intermediários. De acordo com a Política Nacional de Atenção Básica ao Paciente Crítico (2005), essa é uma unidade destinada a pacientes que necessitam de observação mais rigorosa e de procedimentos de baixa ou média complexidade em terapia intensiva para sua sobrevivência.

A paciente da UCl acompanhada pela voluntária não conseguia se locomover realizava apenas movimentos com as mãos. Contudo, era uma das únicas que conseguia se comunicar e, por ser uma adolescente de 17 anos, as atividades efetuadas eram mais coerentes com sua idade, como por exemplo, aulas de idioma. Normalmente as visitas ocorriam três vezes na semana, da $11 \mathrm{~h}$ às $12 \mathrm{~h}$. Devido ao envolvimento na atividade, as visitas passaram a ser cinco vezes na semana, pois o vínculo profissional estreitou a amizade. 
Lopes (2018) apresenta o vínculo criado entre pacientes e profissionais da saúde como instrumento mediador no processo de cuidado, explorando esse relacionamento para aproximação com o espaço público, desvinculando a ideia de amizade referente ao universo privado e doméstico. Ou seja, sentir-se confortável e em um ambiente de reciprocidade faz com que o trabalho executado seja mais efetivo. Uma experiência interessante foi quando em uma das visitas diárias ocorreu à internação de uma criança advinda da selva, que não falava espanhol, mas sim Quíchua nortenho, sendo essa uma língua típica da Amazônia peruana. Diante desta situação as atividades realizadas não possuíam tanta comunicação, eram mais voltadas para desenhos e brincadeiras com bonecas. Frente a isso, nota-se que as barreiras linguísticas podem vir a afetar a qualidade da prestação de cuidados de saúde, limitando a compreensão e o diálogo. Uma alternativa plausível para isso é a presença de um interprete para garantir um melhor atendimento. Ao que tange a população pediátrica as formas de abordagem tornam-se mais amplas, pois com criança há possibilidade de improvisar utilizando brinquedos, desenhos e até mesmo mímica (OLIVEIRA, 2011).

Ao passar dos dias a voluntária ganhou autonomia para cumprir as visitas e as atividades sozinha, quando necessário. Portanto, após ganho de confiança tanto das responsáveis pelo programa quanto pelas crianças, começou a realização de atividades voltadas para o tema de Educação Alimentar e Nutricional (EAN), de acordo com a possibilidade de cada criança. Trabalhou-se com o reconhecimento de alimentos regionais, frutas de cada território peruano e brasileiro, incentivando sempre a troca de culturas, por meio de figuras para colorir, recortar, colar, jogos e historinhas. Além disso, foi possível acompanhar o horário de lanche de cada criança, conseguindo assim, incentivar o consumo dos alimentos e informar sobre os nutrientes presentes em cada um deles.

Atividades recreativas auxiliam no enfrentamento da doença, garantindo alegria no cotidiano de uma criança hospitalizada. O lúdico faz com que o ambiente hospitalar seja mais humanizado e o brincar torna-se instrumento facilitador no cuidado, ao associar brincadeiras com atividades educacionais além de promover saúde ocorre estimulação do desenvolvimento infantil, pois é dada a criança oportunidade de 
persistir, perseverar, descobrir e raciocinar (PINTO, 2008; JENSEN, 2010; LIMA, 2015).

A Educação Alimentar e Nutricional (EAN), processo que trata sobre temas de nutrição, torna-se de suma importância na formação dos hábitos alimentares de uma criança, sendo abordado de forma educativa através de atividades lúdicas e recreativas (FAGUNDES, 2016).

Referente à alimentação dos pacientes, observou-se que os lanches eram compostos normalmente por fruta, iogurte ou bolacha, variando de criança para criança, levando em consideração as preferências e as especificidades de cada uma. Os alimentos eram trazidos pelas copeiras às dez horas da manhã sendo distribuídos com auxílio dos enfermeiros e se caso necessário pelos voluntários.

Não ocorria monotonia alimentar, pois cada dia a fruta era variada assim como o sabor do iogurte. Em uma conversa rápida com a nutricionista responsável pela ala da neurocirurgia, foi possível compreender que todas as refeições elaboradas eram baseadas, não somente nos aspectos nutricionais, mas também sensoriais e culturais. No entanto, devido à entrada de outros alimentos, sendo estes industrializados na sua maior parte, algumas crianças priorizavam a comida trazida de fora em detrimento da disponibilizada pelo hospital. Nesses casos, a nutricionista conversava com os acompanhantes explicando a importância de os pacientes manterem a dieta hospitalar. Ainda, de acordo com a nutricionista, apesar de ser uma instituição pública, os recursos advindos para a alimentação hospitalar, são satisfatórios, pois cada bloco do hospital possui seu serviço de nutrição e dietética.

O ato de se alimentar não está relacionado apenas com as necessidades biológicas, o processo de alimentação em instituições de âmbito público envolve diversas instâncias, atores e processos, portanto há influências culturais envolvidas. O processo de elaboração de um cardápio deve ter relação entre a cultura regional, sendo as políticas públicas os principais meios de influenciar a identidade cultural na composição do cardápio ofertado aos usuários, seja em escolas ou hospitais (SILVA, 2020).

De modo geral, o serviço prestado pela equipe de saúde do instituto abrangia um cuidado focalizado no bem estar do paciente. Paralelo a isso, apesar das 
atividades do voluntariado serem voltadas para o apoio educacional, o simples ato de acompanhar, conversar e brincar contribui de maneira significativa na promoção da saúde e torna o cenário hospitalar mais humanizado. Exemplo disso, uma paciente em especial durante as visitas passou a se mostrar mais ativa, alegre e aceitar melhor sua situação atual, conforme ilustra o Apêndice B. Ou seja, o bem estar de uma criança hospitalizada vai além dos tratamentos médicos e curativos.

A promoção da saúde dentro de um ambiente hospitalar visa o bem estar de seus pacientes, e para atingir um estado completo de bem estar, deve-se levar em consideração a tríade que engloba o físico, mental e social. Porém ao que tange crianças hospitalizadas muitas vezes, não ocorre estímulo do que há de mais saudável nesta fase da vida, o brincar e se divertir, caracterizados pela essência naturalmente lúdica. $\mathrm{E}$ isso acaba por afetar o tratamento, pois o humor está diretamente ligado na recuperação do paciente, através da sua atuação no sistema imunológico, nos efeitos analgésicos e na estimulação dos hormônios da felicidade (OLIVEIRA, 2008; STUBER, 2009).

\subsection{Visita a universidades e outras atividades culturais}

Ao longo das seis semanas de intercâmbio, além de realizar o trabalho voluntário, foi possível conhecer a cidade de Lima, capital do Peru e outras cidades do país, sendo que cada passeio e viagem agregaram mais conhecimento sobre a cultura peruana.

Pode-se visitar duas grandes universidades peruanas, a Pontificia Universidad Católica Del Peru (PUCP), considerada a primeira universidade privada do país, possuindo em seu território um sítio arqueológico e uma múmia Inca em exposição. Aproveitou-se para conhecer juntamente com a equipe da AIESEC a coordenação do serviço de nutrição do campus, salientando que a universidade não oferta o curso de nutrição, apenas possui uma equipe de nutricionistas atuantes nas cantinas do campus. A segunda universidade visitada foi a Universidade Nacional Mayor de San Marcos (UNMSM), pública e conhecida como a mais antiga da América do Sul e uma das mais antigas do mundo, fundada em 1551, atua até os dias de hoje, tendo como 
um de seus primeiros cursos o de Teologia e Artes, sendo um marco no início da história universitária.

Ao que tange o curso de nutrição, a UNMSM tinha como uma especialidade do Programa Acadêmico de Tecnologia Médica (Dietética e Nutrição), contudo, no ano de 1984 incorporou o programa à Faculdade de Medicina como Escola Acadêmica Profissional de Nutrição. As áreas de nutrição clínica, administração de serviços alimentares e nutrição pública possuem práticas pré-profissionais e para obtenção do título profissional de bacharel em nutrição é necessário um relatório de pesquisa final (UNMSM, 2020).

Ao norte da cidade de Lima, a 3.000 metros de altitude fica a cidade de Huaraz, entre duas cordilheiras, sendo capaz de permitir a sensação térmica das quatro estações do ano em um único dia. Aproveitou-se para conhecer o Nevado Pastoruri, uma montanha de 5.240 metros de altitude, acima do mar, situada no Callejón de Huayalas. Além da geleira Pastoruri, visitamos a Laguna Parón, um dos maiores lagos da cordilheira branca, com 4.200 metros de altitude, e montanhas nevadas ao redor. Para subir em ambos os lugares é necessário tomar o chá de folha de coca, uma planta sagrada da cultura Inca, auxiliando nos efeitos físicos resultantes das grandes altitudes.

Em Paracas na região de Ica, pode-se conhecer a Reserva Nacional de Paracas, uma área natural onde o deserto se encontra com o oceano pacífico, exibindo ilhas com leões marinhos e flamingos, incluindo belas praias. No sudoeste do Peru, ainda na região de Ica encontra-se a Huacachina, possuindo o único oásis da América, em meio ao deserto a vila foi construída ao redor de um lago.

Em Chincha Alta, uma cidade localizada na costa sul, pode-se observar a cultura afro-peruana pouco conhecida. No distrito de El Carmen, o berço do folclore afro descendente, ocorre à festa típica Yunza Negra, tendo como símbolo principal uma árvore carregada de presentes. Além da culinária crioula e um vasto conhecimento sobre a cultura afro-peruana, Chincha oferece lindas praças, museu e o Mercado de Abastos, um grande espaço de comércio, muito conhecido pelas suas Jugueria, lojas de sucos e suas feirinhas. 
Por falar em cultura, Martinelli (2004) identifica as diferenças culturais como oportunidades de entender as particularidades do outro, sendo a vivência instrumento capaz de proporcionar uma relação intercultural. Neste sentido o intercâmbio possibilita o contato com novas realidades gastronômicas, históricas, geográficas e econômicas, tornando-se uma experiência cultural e educacional, frente a isso, a realização de atividades culturais promove aos estudantes intercambistas ganhos que contribuem para a formação acadêmica (SANTOS 2014).

\subsection{As dificuldades da vivência}

No início da vivência a principal dificuldade a ser encarada foi o idioma, pois a autora possuía apenas o básico da língua espanhola, sendo este um fator a prejudicar o entendimento nas conversações. Contudo, ao longo das semanas de intercâmbio pelo fato de estar em total contato com a população peruana e consequentemente com o espanhol, ocorreu um desenvolvimento linguístico, tornando esta dificuldade uma oportunidade de aprendizado.

Ademais, ao final da experiência no mês de março houve à intensificação do Coronavírus (Covid-19) em nível mundial. Felizmente pode-se finalizar o trabalho voluntário, no entanto, o retorno para o Brasil foi adiado devido o fechamento das fronteiras Peruanas, desta forma, surgiu à necessidade de passar o período de quarentena no Peru. Após alguns dias de isolamento a embaixada brasileira informou a realização de voos de repatriação saindo diretamente de Lima para São Paulo, com isso a autora pode retornar para seu país de forma segura, iniciando assim a quarentena em solo Brasileiro ao lado de sua família.

\section{CONSIDERAÇÕES FINAIS}

Com as crescentes mudanças culturais, socioeconômicas e tecnológicas, as exigências do mercado de trabalho aumentam juntamente com a necessidade de profissionais com níveis educacionais mais elevados, capazes de interagir num mundo globalizado e dispostos a se aventurar além de sua zona de conforto, sendo a 
internacionalização, através de seu caráter evolutivo, instrumento de potencialização nas carreiras acadêmicas e profissionais (SANTOS 2014; CARVALHO, 2016).

De maneira complementar, Santos (2014) visualiza o interesse de conhecer algo novo como incentivo para enfrentar novas situações e explorar tudo que o lugar visitado tem a oferecer, impactando a vida de outras pessoas e a própria. Devido ao intercâmbio voluntario realizado ter ocorrido em um hospital para crianças pode-se perceber que a saúde pública, bem como as realidades sociais e culturais variam de país para país. Inserida neste cenário além de ganhos próprios foi possível promover saúde as crianças através do trabalho executado.

A permanência em um ambiente insalubre como o hospital, onde se é afastado das atividades do cotidiano, como estudar, brincar e ver os amigos, além da própria patologia, pode proporciona ansiedade e medo aos pacientes, diante disso, a atividade lúdica torna-se um fator alternante no ambiente, tendo um efeito terapêutico e auxiliando na promoção do bem estar. Ao realizar um trabalho voluntário acompanhando crianças hospitalizadas diariamente, nota-se que de fato atividades e brincadeiras através de socialização e interação proporcionam uma saída do isolamento que a internação provoca (MOTTA, 2004; FAVERO, 2007).

Ao concluir este relato, pode-se dizer que os benefícios decorrentes do intercâmbio voluntário vão além do objetivo do projeto de acompanhar crianças hospitalizadas e auxiliar no seu bem estar, pois sair das fronteiras brasileiras em busca de desafios e novas experiências fez com que a autora do artigo ampliasse a visão do mundo e de si mesma.

Entre todos os conhecimentos agregados, vale ressaltar a oportunidade de trabalhar no maior hospital de referência em saúde da criança do Peru, e entender como funciona a saúde pública de um país com grande valor histórico-cultural. Ademais, o contato diário com a população peruana e as viagens realizadas auxiliaram na compreensão de uma das culturas mais antigas da América do Sul e na prática de um novo idioma.

Com isso, até mesmo as dificuldades encontradas ao longo da experiência foram contornadas, tornando-se instrumentos de grande valia para o desenvolvimento integral da estudante. Pois a vivência em um ambiente desafiador faz com que haja 
um aprimoramento tanto profissional quanto pessoal, apresentando assim o intercâmbio voluntário como uma via de mão dupla, onde se ensina e aprende. Desse modo, acredita-se que esta experiência possa motivar outros estudantes a sair de sua zona de conforto e buscar aprendizados além da universidade.

\section{REFERÊNCIAS}

AIESEC BRASIL. Voluntário Global. Disponível em: <https://aiesec.org.br/ Acessado> em: 15 abr. 2020.

APS, Academia Peruana de Salud. Historia de la Salud en el Perú 2007-2011. Sistema Nacional de Salud. Aseguramiento social en salud. Vol 23. Lima, APS, 2013.

AZEVEDO, Debora. Voluntariado corporativo: motivações para o trabalho voluntário. In: Encontro Nacional de Engenharia de Produção. Foz do Iguaçu, Paraná, out. 2007. Disponível em: <https://producaoonline.org.br/rpo/article/view/55/55 >. Acessado em: 18 jul. 2020.

CARVALHO, Jordana Lopes. et al. Intercâmbio acadêmico internacional: uma oportunidade para a formação do futuro enfermeiro. Rev Enferm Ref., 2016. Disponível em: <http://www.scielo.mec.pt/scielo.php?script=sci_arttext\&pid=S087402832016000300007>. Acessado em: 11 jul. 2020.

FAGUNDES, Andhressa Araújo.; LIMA, Marcelle França.; SANTOS, Christiano Lima. Jogo eletrônico como abordagem não-instrutiva e lúdica na disseminação de conhecimento em educação alimentar e nutricional infantil. IJKEM, Int. J. Knowl. Eng. Manage., v. 5, n. 13. Florianópolis, 2016.

FAVERO, Luciane. et al. A promoção do brincar no contexto da hospitalização infantil como ação de enfermagem: relato de experiência. Cogitare Enferm., v. 12, n. 4, p. 519524, 2007. Disponível em: <https://revistas.ufpr.br/cogitare/article/view/10080>. Acessado em: 01 jul. 2020.

INSN, Instituto Nacional de Salud Del Niño. Disponível em: <http://www.insnsb.gob.pe/> Acessado em: 05 mai. 2020.

JENSEN, Michele Ferraz; SANTOS, Rosane Maria dos; FAVERO, Luciane. Benefícios da utilização do brinquedo durante o cuidado de enfermagem prestado à criança hospitalizada. Rev Gaúcha Enferm., 2010. Disponível em: <https://www.scielo.br/scielo.php?pid=S1983-14472010000200007\&script=sci_arttext>. Acessado em: 09 jul. 2020.

LIMA, Kálya Yasmine Nunes de; SANTOS, Viviane Euzébia Pereira. O lúdico como estratégia no cuidado à criança com câncer. Rev Gaúcha Enferm., 2015. Disponível em: 
<https://www.scielo.br/scielo.php?script=sci_arttext\&nrm=iso\&lng=pt\&tlng=pt\&pid=S1983$14472015000200076>$. Acessado em: 15 jun. 2020.

LOPES, Andreia Aparecida Ferreira. Empoderamento, amizade e cuidado de si: Novas formas de relação de assistência à saúde. Rev Bras Ciências Sociais, v. 33, n. 98, 2018. Disponível em:

<https://www.scielo.br/j/rbcsoc/a/BSnYMLVYjKTqPTtnQYCwrKQ/abstract/?lang=pt>. Acessado em: 12 jun. 2020.

MARTINELLI, Dante. P.;VENTURA, Carla. A. A.; MACHADO, Juliano. R. Negociação Internacional. Ed. Atlas. São Paulo, 2004.

MOTTA, Alessandra Brunoro.; ENUMO, Sônia Regina Fiorim. Brincar no hospital: estratégia de enfrentamento da hospitalização infantil. Psicologia em Estudo, Maringá, v. 9 , n. 1, p. 19-28, 2004.

OLIVEIRA, Ana Luiza Rodrigues de. et al. A língua estrangeira como barreira para o cuidado em saúde. Rev Científica Enfem., São Paulo, 2011. Disponível em: < https://www.recien.com.br/index.php/Recien/article/view/25>. Acessado em: 02 jun. 2020.

OLIVEIRA, Roberta Ramos de; OLIVEIRA, Isabel Cristina dos Santos. Os doutores da alegria na unidade de internação pediátrica: Experiências da equipe de enfermagem. Ref Enferm., 2008. Disponível em: < https://www.scielo.br/pdf/ean/v12n2/v12n2a05.pdf>. Acessado em: 08 jun. 2020

PEREIRA, Márcia Pereira. et al. Extensão universitária e trabalho voluntário na formação do acadêmico em odontologia. Arquivos em Odontologia, v. 47, n. 2, p. 95-103, 2011.

PINTO, Emnielle Borges. et al. Benefícios das atividades lúdicas na recuperação de crianças com câncer. Boletim Academia Paulista de Psicologia, vol. XXVIII, 2008.

POLETI, Lívia Capelani. et al. Recreação para crianças em sala de espera de um ambulatório infantil. Rev Bras Enferm., 2006. Disponível em: < https://www.scielo.br/scielo.php?script=sci_arttext\&pid=S0034-71672006000200021>. Acessado em: 23 jun. 2020

Portaria GM/MS n 1.071, de 03 de julho de 2005. Dispõe sobre a Política Nacional de Atenção ao Paciente Crítico. Consulta Pública. Brasília, DF, 04 jul. 2005. Disponível em: <http://dtr2001.saude.gov.br/sas/PORTARIAS/Port2005/PT-03-CONS.htm>. Acesso em: 10 abr. 2020.

SANTOS, Saulo Ribeiro dos. et al. Turismo e Intercâmbio: Contribuições para a formação discente nos cursos de graduação das instituições de ensino superior de São Luís, Maranhão. Revista de Cultura e Turismo, 2014.

SILVA, Anderson Carlos Da, ARAÚJO, Rosiléa Agostinha De; FERNANDES, George Pimentel. Atravessamentos culturais na merenda escolar. Braz J of Develop., Curitiba, v. 6, n. 7, jul. 2020. 
SOUZA, Kleyde Ventura de. Intercâmbio educacional internacional na modalidade doutorado sanduíche em enfermagem: relato de experiência. Esc Anna Nery Rev Enferm., 2008. Disponível em:

<https://www.scielo.br/j/ean/a/GnRRHPTT8B6R6WnbTHYMcgf/abstract/?lang=pt>. Acessado em: 02 jul. 2020.

STUBER, Margaret. et al. Laughter, Humor and Pain Perception in Children. A Pilot Study, Evidence-Based Complementary and Alternative Medicine, vol. 6, no. 2, pp. 271-276, 2009.

UNMSM. Universidade Nacional Mayor de San Marcos. Escuela Profesional de Nutrición. Disponível em: < nhttps://medicina.unmsm.edu.pe/index.php/en/cooperacion/2013-01-31-0720-51/escuela-de-nutricion> Acessado em: 10 ago. 2020.

WARMLING, Alessandra M. Ferreira. et al. Contribuições das atividades complementares na formação profissional em odontologia. Revista da Abeno, 2012.

WILSON, Luis; VELÁSQUEZ, Aníbal; PONCE, Carlos. La Ley Marco de Aseguramiento Universal en Salud en el Perú: análisis de beneficios y sistematización del proceso desde su concepción hasta su promulgación. Rev Peru Med Exp Salud Pública, 2009. 